\title{
Lixiviação de Saflufenacil e Residual após Períodos de Seca ${ }^{1}$
}

\author{
Saflufenacyl and Residual Leaching after Drought Periods
}

\author{
MONQUERO, P.A. ${ }^{2}$, SABBAG, R. ${ }^{3}$, ORZARI, I. ${ }^{3}$, HIJANO, N. ${ }^{3}$, GALVANI FILHO, M. ${ }^{3}$, \\ DALLACOSTA, V. ${ }^{3}$, KROLIKOWSKI, ${ }^{3}{ }^{3}$ e SILVA HIRATA, A.C. ${ }^{4}$
}

\begin{abstract}
RESUMO - O objetivo deste trabalho foi avaliar a lixiviação de saflufenacil em Latossolo Vermelho-Amarelo (textura média, pH 5,6) e Latossolo Vermelho distrófico (textura argilosa, $\mathrm{pH} 5,2$ e $\mathrm{pH}$ 6,0), assim como os efeitos de períodos de seca no residual desse herbicida. A lixiviação de saflufenacil $\left(0,10 \mathrm{~g}\right.$ i.a ha $\left.\mathrm{ha}^{-1}\right)$ e, adicionalmente, a lixiviação de diuron + hexazinone $\left(1.170+330\right.$ g i.a. ha $\left.{ }^{-1}\right)$ foram avaliadas sob simulação de chuva $(40 \mathrm{~mm})$. O herbicida saflufenacil aplicado em solo argiloso com pH 6,0 apresentou lixiviação até a profundidade de $25 \mathrm{~cm}$, porém ela foi mais pronunciada na faixa de 15 a $20 \mathrm{~cm}$. Quando o herbicida foi aplicado no mesmo solo, mas com pH 5,2, houve lixiviação até a profundidade de $15 \mathrm{~cm}$. Em solo de textura média, a lixiviação foi elevada até a profundidade de $25 \mathrm{~cm}$. Para diuron+hexazinone, no solo argiloso, independentemente do $\mathrm{pH}$, houve lixiviação até $25 \mathrm{~cm}$ de profundidade. Todavia, em solo de textura média a lixiviação ocorreu até $40 \mathrm{~cm}$ de profundidade. Em relação ao efeito residual do saflufenacil após períodos de seca $(0,15,30$, 45, 60 e 90 dias) em um Latossolo Vermelho distrófico (textura argilosa), foi verificado efeito fitotóxico no bioindicador maior ou igual a $80 \%$ até os 28 dias de seca.
\end{abstract}

Palavras-chave: calagem, comportamento, herbicida, solo.

\begin{abstract}
This work aimed to evaluate saflufenacil leaching in Red Yellow Latosol (medium texture, $p H$ 5.6) and Dystrophic Red Latosol (clay texture, pH 5.2 and 6.0) and to evaluate the effect of drought on the residual herbicide. The leaching of saflufenacil $\left(0.10 \mathrm{~g}\right.$ a.i. ha $\left.{ }^{-1}\right)$ and hexazinone + diuron $\left(1,170+330 \mathrm{~g}\right.$ a.i. ha $\left.\mathrm{h}^{-1}\right)$ was evaluated under simulated rainfall of $40 \mathrm{~mm}$. Saflufenacil in clay soil with a pH of 6.0, showed leaching at a depth of $25 \mathrm{~cm}$, but was more pronounced in the range between 15 and $20 \mathrm{~cm}$. When the herbicide was applied in the same soil with $\mathrm{pH}$ 5.2, leaching occurred at depths of 10 to $15 \mathrm{~cm}$. In medium texture, soil leaching occurs up to a depth of $25 \mathrm{~cm}$. In the case of diuron thexazinone, leaching can be seen in clay soil, regardless of $\mathrm{pH}$, up to a depth of $25 \mathrm{~cm}$, up to a depth of $40 \mathrm{~cm}$ in medium soil. Regarding the residual effect of saflufenacil after periods of drought (0, 15, 30, 45, 60 and 90 days) in (clay) Latosol, a phytotoxic effect on the bio-indicator, greater than or equal to $80 \%$, was observed at 28 days of drought.
\end{abstract}

Keywords: liming, behavior, herbicide, soil.

\section{INTRODUÇÃO}

Devido ao seu uso intensivo, os herbicidas são frequentemente detectados em estudos de qualidade em águas superficiais e subterrâneas (Carter, 2000; Tanabe et al., 2001). Nas áreas próximas ao cultivo de cana-de-açúcar registra-se a maior ocorrência de resíduos desses compostos, já que essa é uma das culturas que mais utilizam herbicidas no manejo de plantas daninhas (Southwick et al., 2002; Blanco et al., 2010).

Recebido para publicação em 30.7.2011 e aprovado em 29.11.2011.

2 Professora Adjunta, Centro de Ciências Agrárias, Universidade Federal de São Carlos - UFSC, Rodovia Anhanguera, Km 174, Araras, SP, <pamonque@cca.ufscar.br>; ${ }^{3}$ Alunos de Graduação, Centro de Ciências Agrárias, UFSC, <renan_sabbag@hotmail.com>; <bela.orzari@gmail.com>; <nerianeh@yahoo.com.br>; <mariobarretos@yahoo.com.br>; <victordallacosta@hotmail.com>; <valkrolikowski@hotmail.com>; ${ }^{4}$ Pesquisadora do Polo da Alta Sorocabana, <andreiacs@apta.sp.gov.br>. 
No solo, quando o herbicida é aplicado em pré-emergência, pode sofrer processos de sorção, lixiviação e/ou degradação por efeitos físicos, químicos e biológicos, além de serem absorvidos pelas plantas daninhas e/ou plantas cultivadas (Filizola et al., 2002). Nesse sentido, a lixiviação é a principal forma de transporte no solo das moléculas não voláteis e solúveis em água. Essas moléculas deslocam-se no perfil do solo, acompanhando o fluxo de água, o qual é governado pela diferença de potencial de água entre dois pontos (Prata et al., 2003).

Contudo, esses processos de lixiviação e retenção são dependentes do tipo de solo, das condições climáticas e das características dos produtos. O conhecimento desses fatores permite prever o comportamento de herbicidas nas diferentes classes de solo e seleção de dosagens adequadas, bem como evitar efeitos prejudiciais ao ambiente e às culturas subsequentes (Rossi et al., 2005).

Para herbicidas com elevada capacidade adsortiva, o conteúdo de matéria orgânica do solo é geralmente um fator importante, pois, quanto mais alto, maior será a adsorção do herbicida e, com isso, menor a lixiviação. Em solos arenosos, a lixiviação será ainda maior do que em solos siltosos ou argilosos (Rossi et al., 2005).

Outro ponto importante na dinâmica dos herbicidas no solo é a ocorrência de períodos de seca após a aplicação. Trabalho realizado por Oliveira Jr. et al. (2006) evidenciou que, à medida que aumenta o tempo e o número de irrigações entre a aplicação do herbicida isoxaflutole e a semeadura do bioindicador, há redução no potencial efetivo de controle do herbicida no Latossolo Vermelho distrófico. Os herbicidas de alta solubilidade em água - baixos Kow e Koc - podem ser recomendados para aplicação em épocas secas. Entre os herbicidas registrados para a cultura de cana-de-açúcar, por exemplo, que apresentam essas características, podem-se citar o amicarbazone, imazapic, imazapyr, isoxaflutole e tebuthiuron (Procópio et al., 2008; Correia \& Kronka Jr., 2010).

O saflufenacil é um herbicida desenvolvido para aplicação em pré-emergência, pré-plantio incorporado ou pós-emergência em inúmeras culturas, incluindo cana-de-açúcar, milho, trigo, soja e algodão, para o controle principalmente de dicotiledôneas. Esse herbicida pertence à família dos pirimidinedione, inibindo a enzima protoporfirinogênio oxidase (PROTOX) (Grossmann et al., 2011). O saflufenacil é um herbicida ácido moderado, que apresenta pKa de 4,3, solubilidade em água de $30 \mathrm{mg} \mathrm{L}^{-1}$ a pH 5,0 e $2.100 \mathrm{mg} \mathrm{L}^{-1}$ a pH 7,0 e pressão de vapor de 2,0 10 $10^{-14} \mathrm{~Pa}$ a $25^{\circ} \mathrm{C}$ (Basf Agricultural Produts, 2008).

Solos com alto teor de matéria orgânica e material húmico possuem maior afinidade por saflufenacil; portanto, menos herbicida permanece disponível na solução do solo para que ocorra absorção pelas plantas ou transporte. Desse modo, maior atividade fitotóxica de saflufenacil ocorre em solos com teor de matéria orgânica menor que $1,5 \%$, e a menor atividade ocorre em solos com teor de matéria orgânica maior que $4 \%$, independentemente da textura (Hixson, 2010).

Trabalho realizado por Oliveira et al. (2004) evidenciou influência do $\mathrm{pH}$ na retenção de herbicidas. A retenção do imazaquin foi maior nas áreas com menores valores de $\mathrm{pH}$ e altos teores de matéria orgânica. $\mathrm{O} \mathrm{pH}$ alterou a retenção do herbicida por controlar tanto a natureza iônica dos componentes do solo, matéria orgânica e minerais de argila, quanto a sua especiação. Todavia, o teor de argila não afetou a retenção do imazaquin.

Em razão da escassez de informações quanto ao potencial de movimentação do saflufenacil em solos brasileiros, evidencia-se a necessidade de pesquisas sobre o comportamento desse herbicida no ambiente. O objetivo deste trabalho foi avaliar a lixiviação de saflufenacil em Latossolo Vermelho distroférrico (textura argilosa) com e sem calagem e em Latossolo Vermelho distrófico (textura média), assim como o efeito de períodos de seca no residual desse herbicida.

\section{MATERIAL E MÉTODOS}

\section{Lixiviação de saflufenacil em solos com diferentes caracteristicas}

O experimento foi conduzido em casa de vegetação e a metodologia a seguir foi desenvolvida por Inoue et al. (2002), com algumas 
modificações. Foram feitas análises química e fisica de amostras retiradas de um Latossolo Vermelho distrófico (Embrapa, 1999), nas profundidades de 0-20, 20-35 e $35-50 \mathrm{~cm}$. Adicionalmente, amostras de solo proveniente de um Latossolo Vermelho-Amarelo, com textura média e menor quantidade de matéria orgânica, também foram avaliadas.

Amostras do Latossolo Vermelho distrófico foram acondicionadas em sacos plásticos, sendo adicionada quantidade de calcário equivalente a $6 \mathrm{t} \mathrm{ha}^{-1}(\mathrm{PRNT}=80 \%)$ para elevar o pH do solo a 6,0 (certificado por análise química). Após a mistura do calcário ao solo, as amostras foram mantidas durante os 90 dias subsequentes com umidade suficiente para permitir a reação de neutralização do solo.

Desse modo, a lixiviação dos herbicidas foi avaliada em solo argiloso com pH 5,2 e 6,0, além do solo com textura média, com pH 5,6.

As unidades experimentais foram constituídas de colunas de solos montadas, na ordem de profundidade em que foram retiradas, em tubos de PVC de $10 \mathrm{~cm}$ de diâmetro e $50 \mathrm{~cm}$ de comprimento. Os tubos foram envoltos internamente por uma camada de parafina, a fim de evitar escorrimento lateral da solução do solo. Na parte basal, para reter o solo e permitir a drenagem, foram colocadas telas de sombrite $50 \%$. Após o preenchimento, foi colocada na extremidade superior da coluna de solo uma camada de lã de vidro, no topo da coluna, combinada com papel-filtro, com a função de reduzir o impacto das gotas e de garantir a uniformidade na distribuição dos fluidos.
Em seguida, as colunas de solo foram submetidas à irrigação por capilaridade, até ocorrer saturação no topo, permitindo-se em seguida o escoamento da água durante 48 horas, para restaurar sua capacidade de campo.

O herbicida saflufenacil foi aplicado na dose de 0,10 g i.a. ha ${ }^{-1}$. Como padrão, também foi avaliado o herbicida diuron + hexazinone na dose de $1.170+330 \mathrm{~g}$ i.a. ha ${ }^{-1}$. Foi utilizado pulverizador costal pressurizado com $\mathrm{CO}_{2}$, provido de barra de pulverização contendo dois bicos tipo leque Teejet 110.02, pressão de $196 \mathrm{KPa}$, com volume de calda proporcional a $200 \mathrm{~L} \mathrm{ha}^{-1}$. Os tratamentos foram arranjados em esquema fatorial $2 \times 8$, sendo dois $\mathrm{pHs}$ do solo argiloso e oito profundidades de análise, para cada herbicida e quatro repetições. Os dados obtidos foram comparados com testemunhas sem aplicação dos produtos. Adicionalmente, foi avaliada a lixiviação do herbicida em solo de textura média.

Logo após a aplicação dos herbicidas, os tubos foram colocados sob simulador de chuva, com intensidade de precipitação de $1 \mathrm{~mm} \mathrm{~min}^{-1}$, durante o tempo necessário para aplicar a lâmina de água de $40 \mathrm{~mm}$. A simulação de chuva foi feita um dia após a aplicação dos tratamentos (DAT). Após esse processo, as colunas permaneceram em repouso por 72 horas, quando então foram colocadas na posição horizontal e abertas longitudinalmente.

Cada coluna foi dividida em oito seções de $5 \mathrm{~cm}$, medidas a partir da superfície onde os herbicidas foram aplicados. Em cada seção foi

Tabela 1 - Características físico-químicas do solo, na camada de 0-20 cm

\begin{tabular}{|c|c|c|c|c|c|c|c|c|c|c|c|c|c|}
\hline \multirow{2}{*}{$\begin{array}{l}\text { Profundi- } \\
\text { dade }(\mathrm{cm})\end{array}$} & $\mathrm{pH}$ & $\mathrm{MO}$ & $\mathrm{P}$ & $\mathrm{K}$ & $\mathrm{Ca}$ & $\mathrm{Mg}$ & $\mathrm{Al}+\mathrm{H}$ & \multirow[t]{2}{*}{ SB } & $\mathrm{CTC}$ & \multirow{2}{*}{$\begin{array}{l}\mathrm{V} \% \\
(\%) \\
\end{array}$} & \multirow{2}{*}{\multicolumn{3}{|c|}{$\left(\mathrm{g} \mathrm{kg}^{-1}\right)$}} \\
\hline & $\left(\mathrm{CaCl}_{2}\right)$ & $\left(\mathrm{g} \mathrm{dm}^{-3}\right)$ & $\left(\mathrm{mg} \mathrm{dm}^{-3}\right)$ & \multicolumn{4}{|c|}{$\left(\mathrm{mmol}_{\mathrm{c}} \mathrm{dm}^{-3}\right)$} & & & & & & \\
\hline \multicolumn{14}{|c|}{ Lvd } \\
\hline $0-20$ & 5,2 & 24 & 7 & 0,8 & 20 & 9 & 29 & 29,8 & 58 & 51 & 540 & 320 & 140 \\
\hline $20-35$ & 5,6 & 20 & 4 & 1,0 & 18 & 8 & 23 & 27,0 & 50 & 54 & 520 & 330 & 150 \\
\hline $35-50$ & 5,4 & 18 & 4 & 1,1 & 18 & 8 & 24 & 27,1 & 51 & 53 & 520 & 330 & 150 \\
\hline \multicolumn{14}{|c|}{ Lva } \\
\hline $0-20$ & 5,6 & 16 & 4 & 2,3 & 28 & 11 & 24 & 41,3 & 65,3 & 63 & 320 & 170 & 510 \\
\hline $20-35$ & 5,5 & 14 & 3 & 1,5 & 23 & 8 & 25 & 32,5 & 57,5 & 56 & 340 & 160 & 500 \\
\hline $25-50$ & 5,5 & 13 & 3 & 1,6 & 21 & 6 & 25 & 28,6 & 53,6 & 53 & 330 & 180 & 490 \\
\hline
\end{tabular}

Lvd - Latossolo Vermelho distrófico; LVa - Latossolo Vermelho-Amarelo. 
semeada uma linha continua de sementes de pepino (Cucumis sativus), cuja planta é indicadora de injúrias e sensivel ao herbicida em teste preliminar.

Aos 21 dias após a semeadura (DAS), foram observadas visualmente possiveis alterações nas plântulas, caracterizadas como efeitos fitotóxicos dos produtos. Essas avaliações foram baseadas em critérios qualitativos, segundo ALAM (1974), com escala percentual de notas, em que 0 corresponde a nenhuma injúria na planta e 100 à morte das plantas. Além da análise visual, também foi determinada, aos 21 DAT, a biomassa da parte aérea das plantas indicadoras.

\section{Comportamento de saflufenacil em diferentes periodos de seca}

O experimento foi instalado em casa de vegetação. As amostras do solo utilizado no ensaio foram provenientes de um solo Latossolo Vermelho distrófico. As características químicas e físicas das amostras do solo são apresentadas na Tabela 2.

As amostras do solo foram peneiradas e secas ao ar, sendo posteriormente acondicionadas em vasos plásticos com capacidade de $5 \mathrm{~L}$, sendo cada vaso uma unidade experimental com quatro repetições.

O herbicida saflufenacil $\left(0,10 \mathrm{~g}\right.$ i.a ha $\left.{ }^{-1}\right)$ foi submetido a seis períodos de seca $(0,15$, 30, 45, 60 e 90 dias após a aplicação - DAA), utilizando Cucumis sativus como planta indicadora. As plantas foram comparadas com uma testemunha, sem aplicação do herbicida.

O herbicida foi aplicado em pré-emergência, sobre o solo seco, utilizando-se um pulverizador costal de pressão constante, pressurizado por $\mathrm{CO}_{2}$, com pontas do tipo leque XR 110.02, pressão de $196 \mathrm{KPa}$, com volume de calda proporcional a $200 \mathrm{~L} \mathrm{ha}^{-1}$.
Os períodos de seca referem-se ao período de tempo, a partir da aplicação do produto, em que os vasos foram mantidos sem irrigação e semeadura do bioindicador. Transcorridos os períodos de seca previamente estabelecidos, foi realizada a semeadura do bioindicador (três sementes por vaso) e, imediatamente após, aplicada lâmina de $20 \mathrm{~mm}$ de água, considerada suficiente para ativar os produtos que são aplicados no solo (Simoni et al., 2006).

Após a aplicação da lâmina de água, os vasos foram mantidos com irrigação diária até o encerramento das avaliações, aos 21 DAS do bioindicador, ocasião em que a fitotoxicidade foi avaliada visualmente por meio de uma escala percentual de notas, em que 0 corresponde a nenhuma injúria na planta e 100 à morte das plantas. Além da análise visual, também foi determinada a biomassa seca da parte aérea.

Os dados dos dois experimentos foram submetidos à análise de variância e regressão, em função dos diferentes períodos de seca. Os modelos foram escolhidos considerando-se a significância dos coeficientes de regressão, utilizando-se o teste t a $5 \%$ de probabilidade, o coeficiente de determinação e o significado biológico.

\section{RESULTADOS E DISCUSSÃO}

\section{Lixiviação de saflufenacil em solos com diferentes caracteristicas}

No solo argiloso com $\mathrm{pH}$ 6,0 houve lixiviação do herbicida saflufenacil até $25 \mathrm{~cm}$ de profundidade, porém a concentração do herbicida foi maior na faixa de 15 a $20 \mathrm{~cm}$ (Figura 1). Quando o herbicida foi aplicado no mesmo solo, mas com pH 5,2, a lixiviação ocorreu até a profundidade de $15 \mathrm{~cm}$. Desse modo, verifica-se que a elevação do $\mathrm{pH}$ deve favorecer a lixiviação do herbicida saflufenacil. Em solo

Tabela 2 - Características físico-químicas do solo utilizado no experimento

\begin{tabular}{|c|c|c|c|c|c|c|c|c|c|c|c|c|c|}
\hline \multirow{2}{*}{$\begin{array}{c}\text { Amostra } \\
\text { de solo }\end{array}$} & $\mathrm{pH}$ & $\mathrm{MO}$ & $\mathrm{P}$ & $\mathrm{K}$ & $\mathrm{Ca}$ & $\mathrm{Mg}$ & $\mathrm{Al}$ & $\mathrm{SB}$ & $\mathrm{CTC}$ & $\mathrm{V} \%$ & Argila & Silte & Areia \\
\cline { 2 - 21 } & $\left(\mathrm{CaCl}_{2}\right)$ & $\left(\mathrm{g} \mathrm{dm}^{-3}\right)$ & $\left(\mathrm{mg} \mathrm{dm}^{-3}\right)$ & \multicolumn{3}{|c|}{$\left(\mathrm{mmol}_{\mathrm{c}} \mathrm{dm}^{-3}\right)$} & & & \multicolumn{3}{|c|}{$(\%)$} & \multicolumn{2}{|c|}{$\left(\mathrm{g} \mathrm{kg}^{-1}\right)$} \\
\hline Lvd & 5,2 & 24 & 7 & 2,9 & 25 & 13 & 0,6 & 40,9 & 68 & 59 & 540 & 320 & 140 \\
\hline
\end{tabular}

Lvd - Latossolo Vermelho distrófico. 

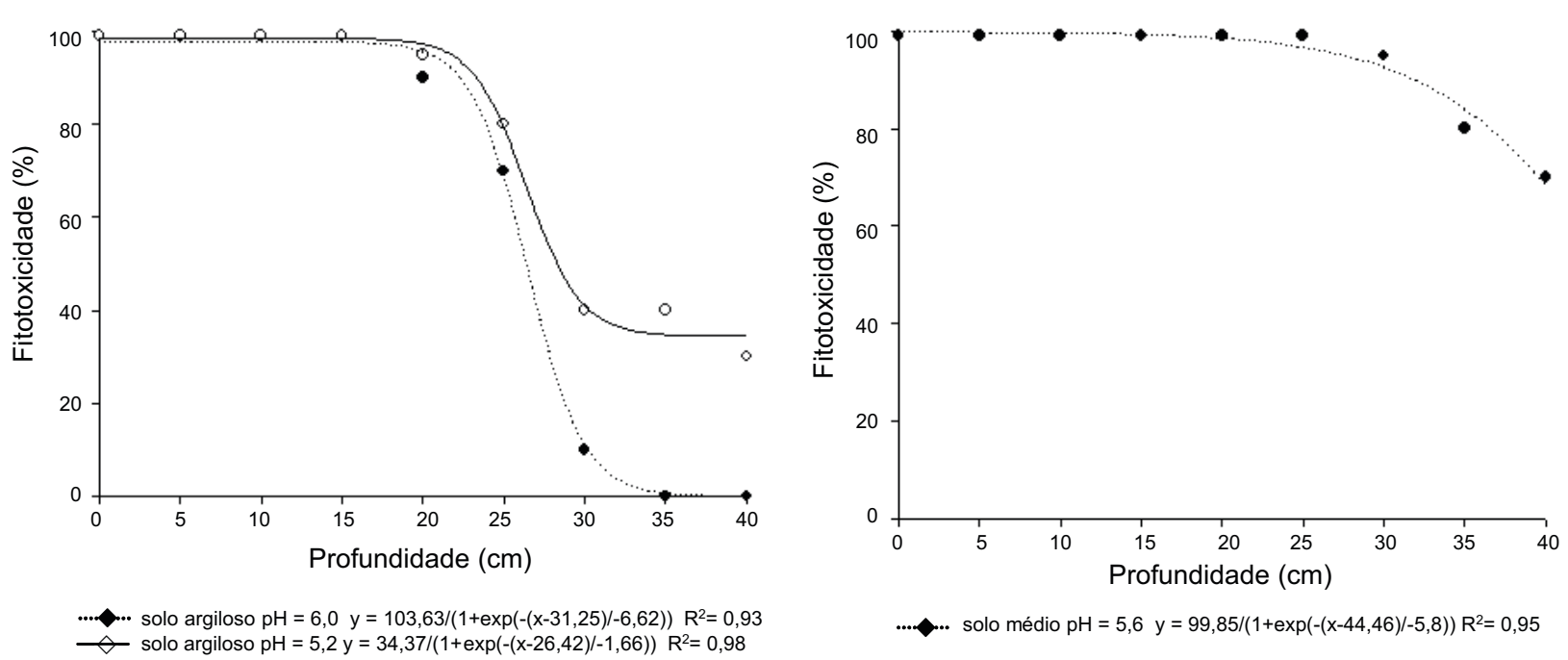

Figura 1 - Lixiviação do saflufenacil em solo argiloso com pH 6,0 e pH 5,2 e em solo de textura média com pH 5,6, após a simulação de $40 \mathrm{~mm}$ de chuva um dia após a aplicação.

com textura média ( $\mathrm{pH} 5,6)$, a lixiviação ocorreu de maneira mais pronunciada até a profundidade de 20 a $25 \mathrm{~cm}$. Assim, a textura do solo apresentou maior impacto no incremento da lixiviação do saflufenacil do que o $\mathrm{pH}$ do solo. A influência do $\mathrm{pH}$ na lixiviação desse herbicida pode ser explicada, pois o pKa do saflufenacil é menor que 5,0; assim, permanece primariamente na forma aniônica em quase todos os solos agrícolas (Hixson, 2008). Na forma aniônica, diminui a força de atração entre moléculas do herbicida e as cargas predominantes no solo, o que resulta em menor sorção do herbicida e, consequentemente, maior lixiviação deste no solo (Inoue et al., 2002).

Na Tabela 3 são apresentados os resultados da biomassa seca das plantas indicadoras. Verifica-se que no solo de textura média e $\mathrm{pH} 5,6$ as plantas de pepino apresentaram fitotoxicidade até a faixa de $25-30 \mathrm{~cm}$. No solo de textura argilosa, o bioindicador apresentou maior biomassa em maiores profundidades no pH 5,2 em relação ao $\mathrm{pH} 6,0$, o que indica maior lixiviação no maior valor de $\mathrm{pH}$. Considerando que o saflufenacil possui pKa de 4,3, o aumento de $\mathrm{pH}$ em mais de uma unidade pode favorecer a dessorção, já que a maior concentração do produto estará na forma aniônica. Resultados obtidos por Inoue et al. (2002) relatam que o incremento no nível de calagem proporcionou significativo aumento do potencial de lixiviação de imazaquin (150 $\left.\mathrm{g} \mathrm{ha}^{-1}\right)$ nas colunas de Latossolo Vermelho distrófico e Latossolo Roxo distroférrico. Assim, níveis mais elevados de calagem apresentam maior potencial de lixiviação desse herbicida. Rocha et al. (2000) observaram que a elevação do $\mathrm{pH}$ também diminuiu a sorção de imazaquin em um Latossolo Vermelho acriférrico. Além das características físico-químicas das

Tabela 3 - Valores médios da massa seca da parte aérea de plantas de pepino cultivadas em solos submetidos à aplicação de saflufenacil seguido de $40 \mathrm{~mm}$ de chuva, em solo argiloso com diferentes $\mathrm{pH}$ e solo de textura média

\begin{tabular}{|c|c|c|c|}
\hline \multicolumn{4}{|c|}{ Peso da massa seca (g) } \\
\hline \multicolumn{4}{|c|}{ Simulação de $40 \mathrm{~mm}$ de chuva 1 DAT } \\
\hline $\begin{array}{l}\text { Profundidade } \\
\text { na coluna }(\mathrm{cm})\end{array}$ & $\begin{array}{c}\text { Solo textura } \\
\text { média }(\mathrm{pH} 5,6)\end{array}$ & $\begin{array}{c}\text { Solo argiloso } \\
(\mathrm{pH} 5,2)\end{array}$ & $\begin{array}{c}\text { Solo argiloso } \\
(\mathrm{pH} 6,0)\end{array}$ \\
\hline $0-5$ & $0,012 \mathrm{~b}$ & $0,010 \mathrm{bA}$ & $0,010 \mathrm{cA}$ \\
\hline $5-10$ & $0,012 \mathrm{~b}$ & $0,011 \mathrm{bA}$ & $0,010 \mathrm{cA}$ \\
\hline $10-15$ & $0,013 \mathrm{~b}$ & $0,030 \mathrm{bA}$ & $0,011 \mathrm{cA}$ \\
\hline $15-20$ & $0,013 \mathrm{~b}$ & $0,050 \mathrm{bA}$ & $0,011 \mathrm{cA}$ \\
\hline $20-25$ & $0,013 \mathrm{~b}$ & $0,081 \mathrm{abA}$ & $0,030 \mathrm{bA}$ \\
\hline $25-30$ & $0,030 \mathrm{~b}$ & $0,078 \mathrm{abA}$ & $0,050 \mathrm{bA}$ \\
\hline $30-35$ & $0,078 \mathrm{a}$ & $0,101 \mathrm{aA}$ & $0,087 \mathrm{abA}$ \\
\hline $35-40$ & $0,096 \mathrm{a}$ & $0,140 \mathrm{aA}$ & $0,130 \mathrm{aA}$ \\
\hline $\mathrm{CV} \%$ & 25,98 & & \\
\hline
\end{tabular}

Médias com letras iguais minúsculas na coluna para o solo com textura média e letras iguais minúsculas na coluna e maiúsculas na linha para o solo com textura argilosa não diferem entre si pelo teste de Tukey a $5 \%$ de probabilidade. Massa seca média da testemunha em solo arenoso $=0,089 \mathrm{~g}$; solo argiloso $\mathrm{pH} 5,2=$ $0,132 \mathrm{~g}$; e solo argiloso $\mathrm{pH} 6,0=0,142 \mathrm{~g}$. 
moléculas (pKa, S, Kow), a movimentação destas depende também dos atributos físicos, químicos e biológicos do solo, como textura, mineralogia, teor de matéria orgânica, $\mathrm{pH}$, CTC, atividade microbiana, entre outros (Prata, 2003).

De acordo com Hixson (2008), as doses requeridas para inibir o desenvolvimento de plantas de canola aumentaram com o incremento do teor de matéria orgânica do solo e decresceram com o aumento do teor de areia.

Para o diuronthexazinone (Figura 2), a lixiviação pode ser visualizada em solo argiloso, independentemente de $\mathrm{pH}$, até a faixa de 20 a $25 \mathrm{~cm}$ de profundidade; todavia, no solo de textura média se estendeu até a faixa de $35-40 \mathrm{~cm}$ de profundidade. Os dados de porcentagem de controle refletem os resultados da biomassa seca (Tabela 4).

A formulação utilizada apresenta alta concentração de hexazinone, que é um ingrediente ativo de alta solubilidade $(29.800 \mathrm{ppm}$ a $\left.25{ }^{\circ} \mathrm{C}\right)$, necessitando de menor umidade no solo para se movimentar e atuar, quando comparado ao diuron (42 ppm a $25^{\circ} \mathrm{C}$ ) (Bouchard et al., 1985). Na Geórgia (EUA) foi detectado hexazinone tanto na água de escoamento superficial quanto no fluxo descendente de água no solo por vários meses após a aplicação de uma dose de 1,62 $\mathrm{kg} \mathrm{ha}^{-1}$ (Bouchard et al. 1985). Esse herbicida é bastante utilizado no manejo de plantas daninhas na cultura da cana-de-açúcar; portanto, a conjunção de elevada utilização, alto potencial lixiviador e solos de baixa capacidade de retenção (baixo teor de matéria orgânica) sugere uma situação de risco acentuado de lixiviação.

Deve-se esperar correlação inversa entre o potencial de lixiviação e a capacidade de adsorção do solo, ou seja, solos argilosos tendem a adsorver mais as moléculas de herbicidas, enquanto nos arenosos a lixiviação pode ser favorecida. Herbicidas ácidos, como o saflufenacil, são repelidos pelas argilas em condições de $\mathrm{pH}$ do solo neutro, mas são sorvidos através de mecanismos de ligação física ou química em condições de $\mathrm{pH}$ ácido, quando estão na forma molecular (Grey et al., 1997). Por essa razão, o aumento do $\mathrm{pH}$ do solo proporciona maior concentração de herbicidas ácidos aniônicos que permanecem na solução do solo e disponiveis para absorção pelas plantas ou dissipação. Além disso, o movimento de agroquímicos através do perfil do solo é influenciado pela infiltração de água; assim, para os herbicidas potencialmente lixiviáveis, esperase correlação positiva entre a precipitação e a lixiviação. Em razão disso, precipitações intensas podem promover a lixiviação desses produtos e contaminar as águas subsuperficiais.
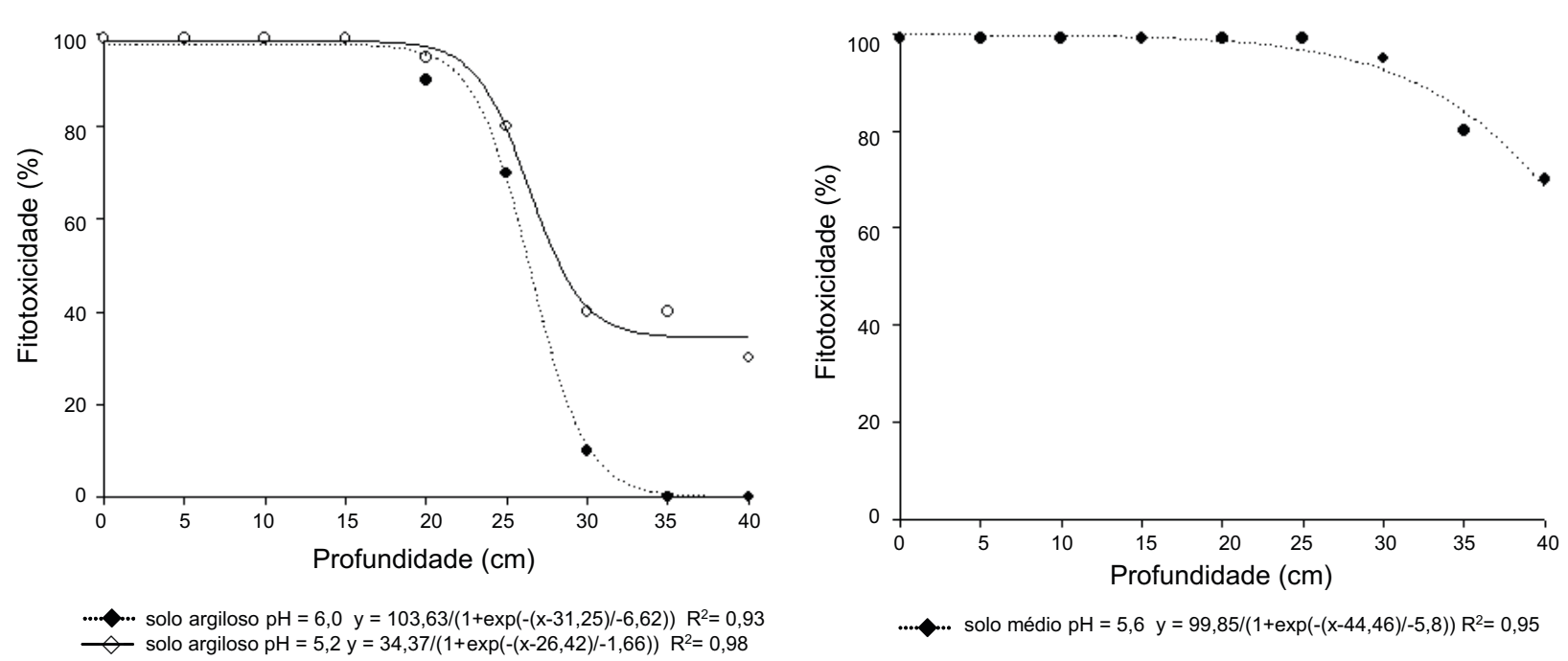

Figura 2 - Lixiviação do diuron+hexazinone em solo argiloso com pH 6,0 e pH 5,2 e em solo de textura média pH 5,6, após a simulação de $40 \mathrm{~mm}$ de chuva um dia após a aplicação. 
Tabela 4 - Valores médios da massa seca da parte aérea de plantas de pepino cultivadas em solos submetidos à aplicação de diuron + hexazinone seguido de $40 \mathrm{~mm}$ de chuva, em solo argiloso com diferentes $\mathrm{pH}$ e solo de textura média

\begin{tabular}{|c|c|c|c|}
\hline \multicolumn{4}{|c|}{ Peso da massa seca $(\mathrm{g})$} \\
\hline \multicolumn{4}{|c|}{ Simulação de 40 mm de chuva 1 DAT } \\
\hline $\begin{array}{c}\text { Profundidade } \\
\text { na coluna }(\mathrm{cm})\end{array}$ & $\begin{array}{c}\text { Solo textura } \\
\text { média (pH 5,6) }\end{array}$ & $\begin{array}{c}\text { Solo argiloso } \\
(\mathrm{pH} 5,2)\end{array}$ & $\begin{array}{c}\text { Solo argiloso } \\
(\mathrm{pH} 6,0)\end{array}$ \\
\hline $0-5$ & $0,011 \mathrm{~b}$ & $0,010 \mathrm{bA}$ & $0,010 \mathrm{cA}$ \\
\hline $5-10$ & $0,010 \mathrm{~b}$ & $0,012 \mathrm{bA}$ & $0,011 \mathrm{cA}$ \\
\hline $10-15$ & $0,011 \mathrm{~b}$ & $0,012 \mathrm{bA}$ & $0,011 \mathrm{cA}$ \\
\hline $15-20$ & $0,012 \mathrm{~b}$ & $0,013 \mathrm{bA}$ & $0,010 \mathrm{cA}$ \\
\hline $20-25$ & $0,012 \mathrm{~b}$ & $0,030 \mathrm{bA}$ & $0,030 \mathrm{bcA}$ \\
\hline $25-30$ & $0,040 \mathrm{ab}$ & $0,080 \mathrm{abB}$ & $0,141 \mathrm{abcA}$ \\
\hline $30-35$ & $0,052 \mathrm{a}$ & $0,147 \mathrm{aA}$ & $0,172 \mathrm{aA}$ \\
\hline $35-40$ & $0,072 \mathrm{a}$ & $0,170 \mathrm{aA}$ & $0,169 \mathrm{aA}$ \\
\hline CV\% & 19,70 & \multicolumn{2}{|c|}{25,23} \\
\hline
\end{tabular}

Médias com letras iguais minúsculas na coluna para o solo com textura média e letras iguais minúsculas na coluna e maiúsculas na linha para o solo com textura argilosa não diferem entre si pelo teste de Tukey a $5 \%$ de probabilidade. Massa seca média da testemunha em solo arenoso $=0,089 \mathrm{~g}$; solo argiloso $\mathrm{pH} 5,2=$ $0,132 \mathrm{~g}$; e solo argiloso $\mathrm{pH} 6,0=0,142 \mathrm{~g}$.

Resultados de trabalho com lixiviação do saflufenacil através de resíduos culturais evidenciaram a seguinte ordem na facilidade de lixiviação em resíduos culturais: saflufenacil $>$ mesotrione $>$ isoxaflutole $>$ oxyfluorfen $>$ flumioxazin, especialmente quando a chuva ou irrigação é limitante. De acordo com os autores, independentemente do tipo de resíduo de colheita, a maioria do saflufenacil lavado ocorreu com os primeiros $32 \mathrm{~mm}$ de chuva ou irrigação (Hixson, 2008).

Tendo em vista os resultados apresentados, conclui-se que o herbicida saflufenacil apresentou elevada lixiviação em solo com textura média e moderada em solo com textura argilosa, sendo mais pronunciada quando submetido à calagem.

\section{Comportamento de saflufenacil em diferentes periodos de seca}

$\mathrm{Na}$ Figura 3A podem ser visualizados os dados de fitotoxicidade do herbicida saflufenacil no bioindicador após os períodos de seca predeterminados. Pela equação de regressão ajustada aos dados, verifica-se que na semeadura do bioindicador em solo com o herbicida aplicado sem intervalo de seca houve controle de aproximadamente 97\%. Entretanto, com 15 dias de seca após a aplicação do saflufenacil, houve controle de aproximadamente $91 \%$. Com a aplicação do herbicida seguida de 30 dias sem chuva, o controle foi reduzido para cerca de $78 \%$. Com 45, 60 e 90 dias de seca, as porcentagens de controle foram reduzidas para 58,36 e $8 \%$, respectivamente.

Desse modo, de acordo com os dados, verifica-se que a redução no controle em relação ao período de 0 dia sem seca foi de $6,19,39$, 61 e $89 \%$ aos 15, 30, 45, 60 e 90 dias de seca após a aplicação, respectivamente. Considerando $80 \%$ como um controle mínimo razoável, o período de seca máximo permitido para obtenção desse percentual de controle seria de 28 dias após a aplicação do herbicida.

Em relação à biomassa seca do bioindicador, na Figura 3B pode ser visualizado o incremento desta com o aumento dos intervalos de seca. A biomassa seca foi de aproximadamente 0,$013 ; 0,043 ; 0,123 ; 0,263 ; 0,392$; e 0,479 gramas por planta aos $0,15,30,45,60 \mathrm{e}$ 90 dias de seca, respectivamente. Observa-se que, no intervalo de 90 dias após a aplicação do herbicida sem chuva, a biomassa do bioindicador é cerca de 35 vezes maior que a constatada na aplicação ao 0 dia.

Segundo informação do fabricante, o saflufenacil é um herbicida não volátil (PV de $\left.2 \times 10^{-4} \mathrm{mmHg}\right)$ e com meia-vida $\left(\mathrm{t}_{1 / 2}\right)$ de uma a cinco semanas. As características que contribuem para manutenção da eficiência dos herbicidas no solo por períodos de seca são: baixa volatilidade, não fotodegradáveis, alta solubilidade, baixa adsorção aos coloides do solo e degradação principalmente via microbiana, uma vez que na condição de solo seco muitos microrganismos passam ao estádio de repouso e tornam-se inativos (Guimarães, 1987). Assim, herbicidas com propriedades químicas diferentes devem apresentar comportamentos distintos quando aplicados em condições de seca.

A utilização de herbicidas pré-emergentes com efeito residual prolongado é um dos fatores que determinam grande eficiência no controle de plantas daninhas durante o período crítico de competição. Com essa alternativa, tornase possivel a execução de planos para o controle efetivo de plantas infestantes na lavoura 

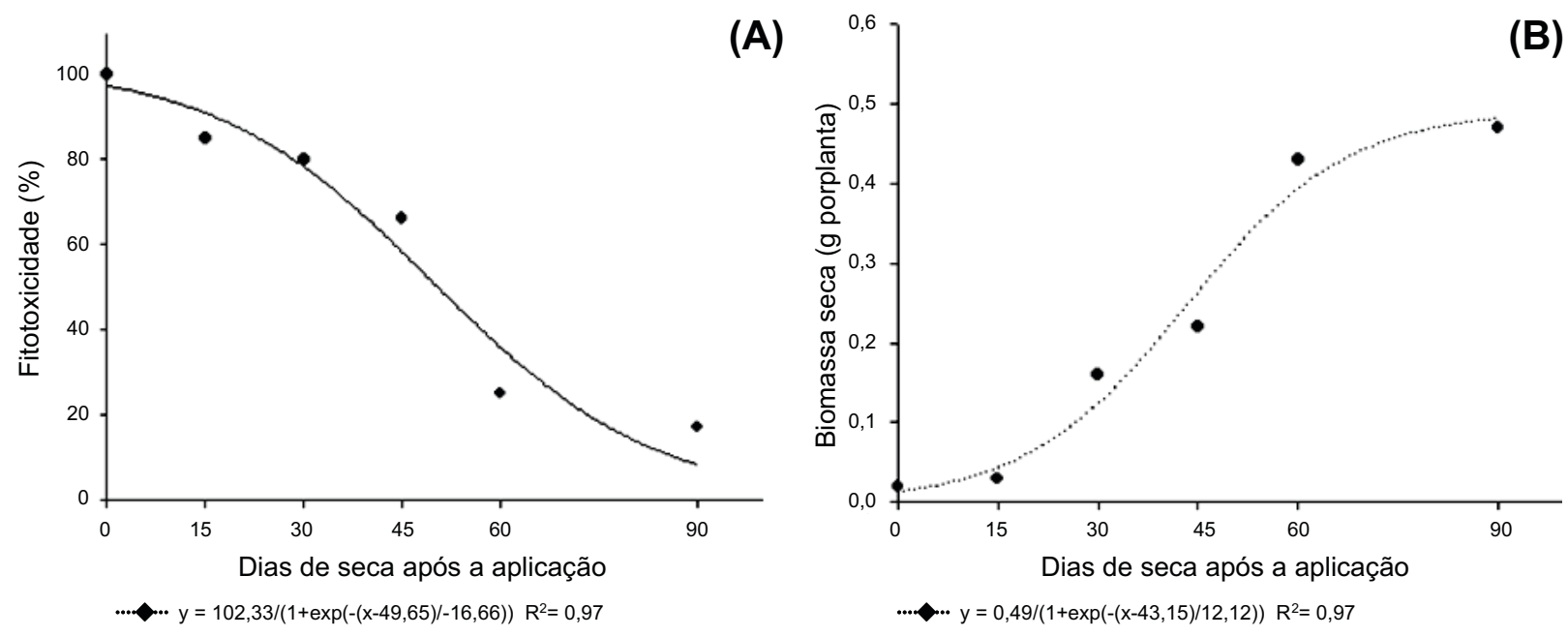

Figura 3 - Fitotoxicidade (A) e biomassa (B) de pepino (C. sativus) semeado em diferentes períodos de seca após a aplicação do herbicida saflufenacil. Massa seca média da testemunha ao longo das avaliações $=0,5 \mathrm{~g}$

(Miller et al., 1995). O imazapyr, por exemplo, submetido a condições de solo seco por período superior a 60 dias teve seu efeito herbicida reduzido no controle do bioindicador (Monquero et al., 2008). No campo, a persistência biológica do imazapyr é dependente da dose e das condições ambientais, com degradação mais rápida em climas quentes e úmidos.

Estudos de dissipação do imazapyr no solo em condições de umidade normal mostram que esse herbicida apresenta resíduos declinando para níveis insignificantes ou não detectáveis dentro de três a sete meses após aplicação, sem atingir profundidade significativa e com pouco movimento lateral no solo (Rodrigues \& Almeida, 2005).

É importante ressaltar que herbicidas aplicados à superfície do solo são frequentemente dissipados, especialmente se houver um período prolongado de seca após a aplicação. É possivel que haja perdas em função do processo de fotodegradação, além de outros fatores que podem estar envolvidos, como a volatilização, acentuada pela temperatura elevada na superficie do solo, a degradação química e biológica e a sorção, que devem ser considerados para explicar o desaparecimento dos herbicidas no solo.

Os resultados permitem concluir que a elevação do $\mathrm{pH}$ e a textura mais leve do solo aumentam o potencial de lixiviação do herbicida saflufenacil no solo. A eficácia do produto é mantida em níveis próximos a $80 \%$ de controle mesmo depois de 28 dias de seca após a aplicação, porém ocorre acentuada queda no desempenho do herbicida após esse período.

\section{LITERATURA CITADA}

ASOCIATION LATINOAMERICANA DE MALEZAS ALAM. Recomendaciones sobre unificación de los sistemas de evaluación em ensayos de control de malezas. ALAM, v. 1, n. 1, p. 35-38, 1974.

BASF Agricultural Products. KIXORTM herbicide: Worldwide Technical Brochure (GL-69288). Agricultural Products Division, Research Triangle Park, NC.2008

BOUCHARD, D. C.; LAVY, T. L.; LAWSON, E. R. Mobility and persistence of hexazinone in a forest watershed. J. Environ. Qual., v. 14, n. 2, p. 229-233, 1985.

BLANCO, F. M. G.; VELINI, E. D.; FILHO, A. B. Persistência do herbicida sulfentrazone em solo cultivado com cana-de-açúcar. Bragantia, v. 69, n. 1, p. 71-75, 2010.

CARTER, A. D. Herbicide movement in soils: principles, pathways and processes. Weed Res., v. 40, n. 1, p. 113-122, 2000 .

EMPRESA BRASILEIRA DE PESQUISA AGROPECUÁRIA - EMBRAPA. Sistema brasileiro de classificação de solos. Brasília: 1999. 412 p.

CORREIA, N. M.; KRONKA JR., B. Eficácia de herbicidas aplicados nas épocas seca e úmida para o controle de Euphorbia heterophylla na cultura da cana-deaçúcar. Planta Daninha [online], v. 28, n. 4, p. 853-863, 2010 
FILIZOLA, H. F. et al. Monitoramento e avaliação do risco de contaminação por pesticidas em água superficial e subterrânea na região de Guairá. Pesq. Agropec. Bras., v. 37, n. 5 , p. $659-667,2002$.

GUIMARÃES, G. L. Impactos ecológicos do uso de herbicidas ao meio ambiente. Série Técn. IPEF, v. 4, n.12, p. 159-180, 1987.

GREY, T. L. et al. Sulfentrazone adsorption and mobility as affected by soil and pH. Weed Sci., v. 45, n.5, p. 733-738, 1997.

GROSSMANN, K. et al. Saflufenacil: Biokinetic properties and mechanism of selectivity of a new protoporphyrinogen IX oxidade inhibiting herbicide. Weed Sci., v. 59, n. 3, p. 290-298, 2011.

HIXSON, A. C. Soil properties affect simazine and saflufenacil fate, behavior, and performance. 2008. $242 \mathrm{f}$. Dissertação (Mestrado em Fitotecnia) - Faculty of North Carolina State University, 2008.

INOUE, M. H. et al. Calagem e o potencial de lixiviação de imazaquin em colunas de solo. Planta Daninha, v. 20, n. 1, p. $125-132,2002$.

MILLER, L. C.; RESENDE, L. C. L.; MEDEIROS, A. M. L. Manejo de herbicidas na lavoura de cana-de-açúcar. STAB, v. 13, n. 1, p. 9-13, 1995.

MONQUERO, P. A. et al. Eficiência de herbicidas préemergentes em períodos de seca. Planta Daninha, v. 26, n. 1, p. 185-193, 2008.

OLIVEIRA JR., R. S. et al. Influência do período de restrição hídrica na atividade residual de isoxaflutole no solo.

Planta Daninha, v. 24, n. 4, p. 733-740, 2006.
OLIVEIRA, M. F. et al. Sorção do herbicida imazaquin em Latossolo sob plantio direto e convencional. Pesq. Agropec. Bras., v. 39, n. 8, p. 787-793, 2004.

PRATA, F. et al. Glyphosate sorption and desorption in soils with different phosphorous levels. Sci. Agric., v. 60, n. 1, p. 175-180, 2003.

PROCÓPIO, S. O.; SILVA, A. A.; VARGAS, L. Manejo e controle de plantas daninhas em cana-de-açúcar. In: VARGAS, L.; ROMAN, E. S. Manual de manejo e controle de plantas daninhas. 2.ed. Passo Fundo: Embrapa Trigo, 2008. $780 \mathrm{p}$

ROCHA, W. S. D. et al. Influência do pH na sorção de imazaquin em um Latossolo Vermelho acriférrico. R. Bras. Ci. Solo, v. 24, n. 3, p. 649-655, 2000

RODRIGUES, B. N.; ALMEIDA, F. S. Guia de herbicidas. 5.ed. Londrina: Edição dos Autores, 2005. 591 p.

ROSSI, C. V. S.; ALVES, P. L. C. A.; MARQUES JUNIOR J. Mobilidade do sulfentrazone em Latossolo Vermelho e em Chernossolo. Planta Daninha, v. 23, n. 4, p. 701-710, 2005.

SIMONI, F. et al. Eficácia de imazapic e sulfentrazone sobre Cyperus rotundus em diferentes condições de chuva e palha de cana-de-açúcar. Planta Daninha, v. 24, n. 4, p. 769-778, 2006.

SOUTHWICK, L. M. et al. Potential influence of sugarcane cultivation on estuarine water quality of Louisiana's gulf coast. J. Agric. Food Chem., v. 50, n. 15, p. 4393-4399, 2002 .

TANABE, A. et al. Seasonal and special studies on pesticides residues in surface eaters of the Shinano river in Japan. J. Agric. Food Chem., v. 49, n. 6, p. 3847-3852, 2001. 